\title{
White Spot Lesions: Recent Detection and Treatment Methods
}

\author{
İsmail Serhat Sadıkoğlu (ii) \\ Department of Restorative Dentistry, Near East University, School of Dentistry, Nicosia, Cyprus
}

ORCID iD of the author: i.S.S. 0000-0002-8608-6348.

Cite this article as: Sadıkoğlu is. White Spot Lesions: Recent Detection and Treatment Methods. Cyprus J Med Sci 2020; 5(3): 260-6.

\begin{abstract}
Nowadays, the importance of detecting and treating carious lesions before they turn into irreversible cavitations in dental tissue has been understood. The white spot lesion is the first visual finding of enamel caries. At this stage, it is possible to stop the caries formation and even heal the formed sub-surface lesion by various methods. Most dentists have difficulties while choosing preventive or interventional treatment methods for these situations. In line with the basics of minimally invasive dentistry, this review aims to provide an understanding of the histological character of white spot lesions and to inform clinicians about current methods of detection and treatment, and to approach these cases in their clinical routine with a minimally invasive perspective.
\end{abstract}

Keywords: White spot lesion, resin infiltration, remineralization, DiagnoCam, soprolife, fluorecam

\section{INTRODUCTION}

The stage before cavitation in the development of dental caries is called white spot lesion. It is characterized by subsurface demineralization areas formed under an intact enamel surface $(\mathrm{I})$. The mineral content in the affected area is reduced, which in turn affects the translucent feature of the enamel, and the color of these areas appears more opaque white. Hence, initial enamel lesions or flat surface caries are also called white spot lesions (2). They are the first visible findings in caries formation and are considered as initial lesions by many clinicians. However, it should be remembered that demineralization must have a minimum depth of 300-500 $\mu \mathrm{m}$ to be visible (3). In actual practice, it is important to differentiate the etiology of these lesions because they can be due to caries or even hereditary. Lesions originating from caries progression become apparent opaque and chalky when the tooth surface is dried with air. This appearance is because the enamel tissue in this area loses its translucent feature due to subsurface demineralization. In contrast, developmental lesions are less or not affected by air-drying (4). The aim of the current review is to remain readers about the histological structure of white spot lesions and to provide information about current diagnosis and treatment methods.

\section{Histological Characteristics of White Spot Lesions}

In the carious lesions examined, it was determined that the mineral loss first occurred at the center of the enamel prisms. Although its cause cannot be fully explained, it is thought that the low crystal density at the center of the prism allows acid diffusion from the outside (5). The white spot lesion consists of four histological layers. These layers from the deepest part of the lesion to the surface are translucent layer, dark layer, lesion body, and superficial layer.

\section{Translucent Layer}

The translucent layer showing the direction of the enamel caries has the feature of being the deepest layer of the initial caries lesion. This layer got this name because of its appearance under polarized light after being painted with a quinoline solution that does not contain the structural elements seen in healthy enamel samples. Pores or cavities are formed between prisms with the penetration of hydrogen ions that occur during caries formation. Quinoline solution has the same light refraction coefficient value with the enamel. So, this layer with $1 \%$ pore volume becomes invisible in the polarized microscopy examination when stained with quinoline (6).

\section{Dark Layer}

The second layer that we encounter when coming up more on subsurface is called the dark layer. The reason for this black appearance formed under polarized light is the presence of too many pores in this area that are too small to ab- 
sorb a quinoline solution. Since these pores are filled with air, the affected area appears opaque white in the clinic. Total pore volume in the dark layer varies between $2 \%$ and $4 \%(4,6)$. Some of the researchers working in this field say that this layer was not formed during demineralization, but through shrinking of the larger pores that existed as a result of ion accumulation. An increase in the volume of the lesion body was observed in this region during experimental remineralization. Caries is considered to occur very quickly in lesions where the dark layer is not observed (6). While it does not contain this layer in the first examination, monitoring of its formation in the examinations after the remineralization processes supports the view that the formation of the dark layer is related to the remineralization process (7).

\section{Lesion Body}

During the demineralization phase, the largest part of the initial caries lesion is the lesion body. It is the layer with the most pore volume among the enamel caries layers with its pore volume starting from $5 \%$ at the boundary of the lesion body, expanding to $25 \%$ in the center. Retzius lines are clearly observed within the lesion body, which shows that there is relatively more demineralization in this region compared to other areas and the porous structure is increased. The first penetration of caries into the enamel is in line with the Retzius lines (6).

If the pore volume is wide enough to allow penetration, it is possible to see bacteria in the lesion body. In some studies in which the lesion body was examined using a transmission electron microscope(TEM) and scanning electron microscope (SEM), bacterial invasion was found between the enamel prisms (8).

\section{Superficial Layer}

The migration of calcium and phosphate ions from the enamel prisms that has dissolved at the bottom and the fluoride movement from the mouth to the enamel surface have made the superficial layer more resistant to acid attacks (7). The more durable and intact structure of this layer is not due to the genetic or structural features of the enamel. These beneficial properties are the result of ion exchanges during demineralization/remineralization cycles. In this way, intact enamel surface acts as a barrier against bacterial invasion (6).

\section{Classification of White Spot Lesions}

There are various classifications for white spot lesions, but the

\section{Main Points:}

- Detecting and treating carious lesions before they turn into irreversible cavitations in dental tissue is possible and can be done with a proper patient examination. Today's technology has made it easier for us to detect initial lesions at an early stage.

- Accurate diagnosis and individualized treatment methods according to lesion characteristics, should be used in the treatment of early stage lesions.

- Resin infiltration technique acts as a bridge between non-invasive and invasive methods. Depending on the lesion depth, dental practitioners can use this method alone or combining with other techniques such as bleaching and micro-abrasion. most frequently used method is the International Caries Detection $\bar{a}$ Assessment System (ICDAS) classification, which is created by combining the most successful features of all detection and evaluation systems used in the detection of caries by Ekstrand et al. (9). Although we started to understand the formation of caries and the influencing factors, over the years, it was clear that ICDAS I was inadequate in evaluating the lesion activity. Therefore, ICDAS I was modified in 2004, and ICDAS II was launched (I0).

In ICDAS II, radiographic images of enamel and dentin lesions are also included in the classification. It is divided into five classes as follows:

El: Lesion that reaches the outer half of the enamel E2: Lesion that has advanced to the inner half of the enamel DI: Lesion that is limited to the outer one-third of the dentin

D2: Lesion that has advanced to the middle third of the dentin D3: Lesion that has advanced to the inner one-third of the dentin

\section{Diagnosis Methods for White Spot Lesions}

Nowadays, the importance of diagnosing carious lesions before they turn into irreversible cavitations has been understood. Most dentists have difficulty in deciding when to apply preventive methods and when to intervene. Evaluation of the patient's caries activity is also important in the diagnosis and treatment plan. White spot lesions in a caries-active mouth can quickly turn into cavitations. However, in people with low caries activity, the repair mechanisms will be more effective; therefore, the lesions may have the potential of healing. Hence, it is important to plan the treatment according to the caries activity in individuals after a correct diagnosis (II). The most commonly used diagnostic methods are listed next.

\section{Visual Examination}

The most used diagnostic method in the daily routine of dentists is visual examination (3). It can be determined if a lesion is active or inactive by a visual examination of white spot lesions. Chalky and rough surfaces indicate that the lesion is active, while smooth and shiny surfaces are indicative of an inactive lesion (12).

To perform a visual examination correctly, the tooth surface must be dried with air for at least 5 seconds after cleaning with pumice and then examined with the help of light and mirror (4). Light is very important in the visual examination of white spots. As the existing pores are at the micro-level on the solid enamel with a refractive index of 1.62 , the enamel tissue appears translucent. However, the increase in micro-porosity due to continved demineralization causes a decrease in this refractive index. When the enamel surface gets wet, these pores are filled with water with a refractive index of I.33. Since the refractive index of water is very close to that of healthy enamel, the opacity of the lesion on the enamel surface will not be visible and the lesion cannot be distinguished. In contrast, after the air-drying process, the opaque enamel lesions become evident and distinct from the healthy enamel surface as the pores within the lesion will be filled with air which has a refractive index of I.0 (4). The advantages of this method are that it is simple to use, inexpensive, and clinically valid; whereas, its biggest disadvantage is that the method is difficult to be standardized. 


\section{Evaluation with Digital Photography}

The conventional visual inspection does not provide a physical/ numerical record of the teeth examined. Using a method for remote discussions, such as photography, could bring about a substantial improvement in dental education and case discussion. One would be able to discus clinical situations at a distance by sharing the examination results with professionals based at different locations. Health services are gradually adopting this concept in telemedicine and teledentistry initiatives, with encouraging results, especially in educational and diagnostic applications (I3). Digital dental photography is a field that requires technical sensitivity and education, considering the dark, small, and moist mouth environment as well as the interaction of soft and hard tissues with light. Along with the training, it is recommended to use a light system, such as lateral twin flash or ring flash, and a camera that allows macro lens and lens replacement. The disadvantages of these equipments are that they are big and heavy and their cost is high. However, these disadvantages can be eliminated, thanks to the camera and photo shooting features of smart phones, which have become very popular today (14).

\section{Fluorescence Techniques}

The autofluorescence feature of the enamel decreases because of demineralization. These optical changes are directly related to the mineral content of the enamel (I5). Therefore, autofluorescence principle is used in early caries diagnosis to show mineral loss. Clinically, the brands that use the fluorescence feature are DIAGNOdent (KaVo Dental Corporation, Biberach, Germany) and QLF (Inspektor Research Systems BV, Amsterdam, The Netherlands).

\section{Quantitative light-induced fluorescence (QLF)}

Generally, light spreads much faster in carious lesions than healthy dental tissues. Therefore, light absorption and fluorescence in the region of carious lesions is decreased. In this way, light emission measures can be used to evaluate the mineral loss. QLF technique works on this principle of fluorescence (16).

In recent years, FluoreCam (Therametric Technologies, Inc., Noblesville, IN, USA), a portable device that operates on the QLF principle, is available which is easier to use and carry. It stimulates the tooth surface with intense light and analyzes the resulting fluorescence image with its special software. As a result of the evaluation, three numerical data appear, indicating the size, density, and effect of the demineralized enamel lesion. There is no need for a darkroom as in case of QLF device while measuring, which makes it easier to use (17).

\section{Laser Fluorescence}

The DIAGNOdent pen has been developed for early diagnosis of carious lesions on occlusal and flat surfaces of teeth. This device emits a visible light of 638-655 nm wavelength using a diode laser, which is absorbed by organic and inorganic substances in the tooth structure, thereby the structures creating infrared fluorescence photons (18). The filtered fluorescence signals are collected with a different fiber bundle at the same tip that emits the light and are shown by a photodiode with scores from 0 to 99. The density of the recovered photons is directly related to the depth of the lesion. Scores greater than or equal to 20 and 25 indicate the presence of carious lesions. Higher values indicate greater caries penetration depth (I8). Rodriguez et al. (19), reported that while the laser fluorescence method was effective in detecting the first demineralization in enamel, it was not effective in monitoring the progress of the lesion and was found insufficient to measure small changes in the mineral content. To improve this situation, the idea of examining the initial enamel lesion with laser fluorescence method after dying the lesion with a fluorescent dye was born and found successful (18).

The SoproLife camera is a modern caries detection method, based on laser induced fluorescence. This new method combines the advantages of visual examination, through a high magnification oral camera, and those of a laser fluorescence device (20, 21). Kockanat and Unal (22) reported that SoproLife camera and ICDAS II showed the highest sensitivity values against other tested detection methods.

\section{Electronic Caries Monitor (ECM)}

ECM is based on the measurement of the electrical resistance of the tooth structure during controlled drying. The electrical resistance value of a tooth depends on the porosity of the measured tooth region, amount of fluid in the porous area, temperature, mobility of the fluid in the porous area, and ion concentration. The ECM allows measurement in the range of I $\mathrm{kW}$ to $>10 \mathrm{GW}$ (23). It has been reported that ECM performs more successfully on flat surfaces and proximal surfaces compared to occlusal surfaces (24).

\section{CarieScan PRO}

The alternating current impedance spectroscopy technique, called the CarieScan PRO, uses multiple frequencies instead of a fixed frequency as used in ECM. The working mechanism is based on the fact that carious and healthy tooth tissues respond diversely to resistance tests at different frequencies (25). However, in a recent study, the CarieScan showed the lowest sensitivity values compared to SoproLife camera, DIAGNOdent pen, and visual examination (22).

\section{Fiber optic transillumination-digital fiber optic transillumination (FOTI-DIFOTI)}

The light transmission coefficient of caries differ from that of healthy teeth structures. During demineralization, which disrupts the dense hydroxyapatite content of the enamel, light photons scatter while trying to pass through the tooth and an optical distortion occurs. Since the light transmission coefficient of the intact enamel is higher than that of carious lesions, dark shadows are observed along the dentinal tubules when the carious tissues are examined with a fiber optic device (16). Initial caries lesions can be distinguished according to the intensity of the shadows formed by the light power of the device.

DIFOTI is a caries diagnosis method that uses the combination of FOTI and a digital camera to compensate for the deficiencies of FOTI. In this system, infrared radiation close to $780 \mathrm{~nm}$ wavelength is used instead of a white light source. This new diagnostic method gives hope in terms of diagnosis of initial caries and measurement of lesion severity because it is not invasive, does not use ionized radiation, and is more sensitive than radiographs in detecting early demineralization (16). 


\section{Near-infrared light transillumination (NILT)}

An X-ray-free, photo-optical method, which is called near-infrared light transillumination (NILT), was released for caries detection in posterior teeth. High contrast between carious lesions and sound tissue can be obtained using this method. The NILT camera system (DIAGNOcam) that emits light at a wavelength of $780 \mathrm{~nm}$ was introduced to the market in 2012. The optical fiber arms of this device transmit light from the gingival and alveolar bones to the root of the tooth and from there to the crown. Then, an image is created from the occlusal surface with a charge-coupled device sensor $(26,27)$. A recent study stated that the DIAGNOcam method accurately detected hidden incipient enamel and dentin caries in primary and permanent teeth compared with other methods (27).

\section{Prevention and Treatment Methods}

Various options are available for the treatment of white spot lesions. Recent approaches are listed next.

\section{Remineralization of White Spot Lesions}

The physiological cycle can be turned into the direction of remineralization by preventing caries and increasing the duration of protective factors in the mouth. Generally, remineralization is a natural repair process, and many methods have been proposed to improve it.

\section{Providing Oral Hygiene}

Tooth caries is a major problem affecting not only the individual, but also the social institutions and health economy. Untreated caries affects more than 600 million children around the world. Such a big problem also creates a huge cost, and countries are looking for cost-effective solutions at the community level. Gaining awareness on individual oral hygiene and habits of daily brushing with fluoride toothpaste is one of the solutions for problems of tooth caries. Providing personal oral hygiene with tooth brushing and flossing is the most effective method that patients can individually perform to change the bacterial plaque composition and thereby change the process of white spot lesion formation (28).

\section{Regulation of the Diet}

Apart from the presence of bacterial plaque, another factor affecting caries formation is diet. Dietary foods not only act as inhibitors of the formation of cavities, but also are among the causes of the formation of caries. For example, some foods with hard and fibrous structure can help with mechanical cleaning, while others show an anti-caries effect by increasing the amount and flow rate of saliva with their taste and smell. Minerals, cocoa, tea, and proteins, such as cheese and milk, have a bacteriostatic effect by changing the metabolism of cariogenic bacteria. However, when fermented carbohydrates are frequently consumed, it may cause caries (29).

\section{Use of Antimicrobial Agents}

Chlorhexidine was released to public for the first time in the USA in the form of $0.12 \%$ mouthwash for periodontal treatments of patients who belonged to a high-risk group. It reduces Streptococcus mutans count and accelerates remineralization. It is recommended to use chlorhexidine mouthwash for 30 seconds just before bedtime because the reduced saliva flow rate at night helps in attaching chlorhexidine more easily to the struc- tures inside the mouth. When chlorhexidine mouthwash is used in this way for 2 weeks, it reduces the number of Streptococcus mutans below the level potential for caries formation, and the effect of this decrease lasts between 12 and 26 weeks (6).

In recent years, the desire to return to the natural products has also affected the view of antimicrobial agents in dentistry. Antimicrobial properties of essential oils obtained from plants instead of artificial molecules are being investigated furthermore. Besra et al. (30) investigated the antimicrobial properties of various plant extracts on caries pathogens and concluded that the plants can be used individually or in combination in the treatment of dental caries.

\section{Fluoride Applications}

Fluoride shows its effect against caries in three different mechanisms. First, the presence of fluoride greatly increases the formation and accumulation of fluorapatite, which is formed by the combination of calcium and phosphate ions in saliva. Fluorapatite is resistant to dissolution; therefore, it replaces salts that contain manganese and carbonate, which are easily dissolved and lost due to demineralization, and makes the enamel more resistant to acids. The second mechanism is the remineralization of the initial cavity lesion with the fluorapatite crystals. The third and last mechanism is the antimicrobial activity of fluoride ions. Low concentrations of fluoride inhibit the production of the glycosyltransferase enzyme. The glycosyltransferase enzyme increases bacterial adhesion and provides glucose for extracellular polysaccharide formation. In high concentrations (I2,000 ppm), topical fluoride applications have a direct toxic effect on oral microorganisms, including mutans streptococci (6). Fluoride applications can be classified as systemic and topical.

\section{Systemic Applications}

Systemic applications are effective methods, especially in individuals with high risk of caries formation and in communities where fluoride usage is low. Fluoridation of waters, which is one way of the systemic applications, shows not only systemic but also topical effect (6). World Health Organization (WHO) reported that consuming I mg of fluoride per day is beneficial for health. Systemic applications of fluoride are fluoridation of drinking water, salts, and milk and addition of fluorinated tablets or drops to the diet.

\section{Topical Applications}

Systemic fluoride intake was thought to be effective for a long time prior to the direct tooth application period. However, today, it is accepted that the use of topical fluoride is more beneficial during dental development and maturation. In high concentrations (12,000 ppm), which are generally applied professionally in dental clinics, topical fluoride has a direct toxic effect on oral microorganisms, including Streptococcus mutans (6). Fluoride varnishes were developed to make the contact time longer, to bond to the enamel for increased periods, and thereby prevent the quick loss of fluoride after application. Varnishes take the role of a reservoir for slow release and facilitate greater fluoride uptake (3I). American Academy of Pediatric Dentistry guideline recommended that 5\% (22,600 ppm) concentration of fluoride varnishes should be applied at least twice in a year for primary teeth and two or four times in a year for permanent teeth (32). 


\section{Casein phosphopeptide-amorphous calcium phosphate (CPP-ACP) applications}

ACP is a tricalcium phosphate containing calcium and phosphate ions in an amorphous structure. When ACP enters a solution, it quickly turns into a stable structure, such as octacalcium phosphate or apatite. Casein is a phosphoprotein that makes up $80 \%$ of the proteins found in cow milk. Keeping calcium and phosphate ions in protein complexes is the most important feature of casein. These ions transform into smaller peptides, such as CPP, making them highly durable. Casein molecules act as a carrier that provides calcium and phosphate ions that can be used by the tissues, such as teeth or bones for remineralization (6). Mendes et al. (33) reported that the use of CPP-ACP was a good alternative for the remineralization of white spot lesions. The effect of remineralization can be improved when this product is applied in combination with fluoride. Although the applications, such as fluorides and CPP-ACP, have a positive effect on stopping caries progression, studies showed that these methods are not sufficient in terms of esthetic improvement according to the ICDAS (34).

\section{Laser Applications}

Laser alters the tooth surface and makes the tooth structure more resistant to dissolution during demineralization by providing recrystallization of hydroxyapatite crystals, changing the organic matrix composition, and differentiating the enamel surface structure and physical properties (35). Alqahtani et al. (36) showed that diode laser irradiation combined with topical fluoride application significantly increased the hardness and improved the esthetic appearance of WSLs compared to no treatment and fluoride treatment alone. In contrast, Molaasadollah et al. (37) reported that use of Er,Cr:YSGG laser irradiation plus $1.23 \%$ Acidulated Phosphate Fluoride gel was not significantly different from the application of fluoride gel alone in enhancing the remineralization of WSLs. The difference between these two studies may be due to the different types of laser used.

\section{Ozone}

It was reported that ozone application can reduce Streptococcus mutans and Streptococcus sobrinus counts on saliva-coated glass beads (38). However, this treatment method can only remove the microorganisms and stop the demineralization activity in the outer half of enamel lesions (39). A recently updated systematic review reported that there is a fundamental need for more evidence and appropriate researches before the use of ozone can be considered a viable alternative to current methods for the management and treatment of dental caries (40).

\section{Microabrasion Applications}

In the microabrasion technique, in addition to the porous enamel layer, stains adhering to these areas are eliminated by applying a mixture containing acid and abrasive particles to the tooth surface with a rubber cap under low pressure, similar to the mixture of pumice and water used during polishing. In this method, the erosive and abrasive particles of the acid are combined and the defective or discolored enamel tissue is eliminated (4I). In this context, microabrasion is not a non-invasive, but minimally invasive treatment technique. Gu et al. (42) reported that microabrasion improved the esthetic appearance of WSLs and showed sufficient durability for 12 months. However, resin infiltration showed a better esthetic improvement effect when compared to microabrasion at 12 months.

\section{Bleaching Applications}

Kim et al. (43) claimed that bleaching of the tooth structure containing white spot lesions may provide a camouflage effect that makes the whiteness of the lesion less visible. It should be remembered that the bleaching process only improves the esthetic appearance with a camouflage effect on WSLs and does not treat the lesion. A recent systematic review showed that bleaching of WSL can diminish color disparities between carious and non-affected areas but researchers also reported that the certainty of the evidence was very low and further prospective in vivo studies are necessary (44).

\section{Resin Infiltration}

According to histological studies, it is a known fact that the microporosity increases in different layers of initial enamel lesions (6). These porous openings and enlarged intercrystalline areas function as points of propagation and passageways for acids and dissolved minerals. Based on this information, instead of completely removing the initial carious lesions as in conventional methods, the idea of filling the porous structure with low-viscosity resins would not only reduce the micropore structure, but also mechanically support the enamel tissue (45).

The resin infiltration method was first developed to stop proximal initial carious lesions (46). It is based on the principle that low-viscosity resins (infiltrants) penetrate the lesion by the effect of capillary forces after erosion of the non-cavitated surface layer, which is a characteristic feature of the white spot lesions. Infiltrant fills the porous lesions and thus, prevents acid and mineral diffusion (47). Resin infiltration shows high esthetic results due to the lesion's camouflage as a side effect during the treatment of white spot lesions (48). Torres et al. (49) showed that the resin infiltration technique gives better esthetic results than fluoride applications and remineralization methods. This success in masking lesions has been attributed to the refraction coefficient (1.52) of the resin used for infiltration that is close to the apatite crystals. In this way, the chalky, opaque appearance of WSL disappears and the color difference ceases to be visible. Perdigao (50) showed that in addition to masking the enamel WSLs, resin infiltration can envelop residual enamel crystallites forming an enamel hybrid layer. This hybridization makes resin-embedded enamel more resistant to acid attack than sound enamel.

\section{CONCLUSION}

It is important to detect and treat carious lesions before they turn into irreversible cavitations. White spot lesions are a stage where caries progression can be detected and arrested. As the histological structure of these lesions are explored and understood, it is emphasized that the application of minimally invasive techniques is the most appropriate approach for treatment. It is possible to stop and reverse caries progression in these lesions with the right application. Many methods have been proposed for the detection and treatment of these lesions. As mentioned above, less-invasive methods should be chosen for the treatment of white spot lesions. All these reasons led to the search for new techniques and materials. As a result of these searches, remineralization approaches with CPP-ACP and fluoride, microabrasion, and recently, resin infiltration methods were introduced. The treatment to be selected when treating these lesions should be based on the individual conditions. The depth, 
formation time, and etiology of the lesion should be taken into consideration, and the right treatment or combination of treatments should be chosen.

Peer-review: Externally peer-reviewed.

Author contributions: Concept - I.S.S Design - I.S.S.; Supervision - I.S.S.; Resource - I.S.S., U.G.; Materials - I.S.S.; Data Collection and/or Processing - I.S.S.; Analysis and/or Interpretation - I.S.S.; Literature Search I.S.S.; Writing - I.S.S.; Critical Reviews - I.S.S.

Conflict of Interest: Author have no conflicts of interest to declare.

Financial Disclosure: The authors declared that this study has received no financial support.

\section{REFERENCES}

I. Kidd EAM, Fejerskov O. What constitutes dental caries? Histopathology of carious enamel and dentin related to the action of cariogenic biofilms. J Dent Res. 2004;83 Spec No C: C35-8. [Crossref]

2. Øgaard B, Rølla G, Arends J. Orthodontic appliances and enamel demineralization. Part I. Lesion development. Am J Orthod Dentofac Orthop 1988; 94(1): 68-73. [Crossref]

3. Axelsson P. Diagnosis and risk prediction of dental caries. Quintessence Pub. Co; 2000.p.307.

4. Fejerskov O, Kidd EAM. Dental caries: the disease and its clinical management. Blackwell Munksgaard; 2008.p.616.

5. DARLING Al. The selective attack of caries on the dental enamel. Ann R Coll Surg Engl 1961; 29(6): 354-69.

6. Roberson, T. M., Heymann, H., Swift, E. J., Sturdevant CM. Sturdevant's art and science of operative dentistry. St. Louis, Mo: Mosby Inc.; 2006.

7. Silverstone LM. The surface zone in caries and in caries-like lesions produced in vitro. Br Dent J 1968; 125(4): 145-57.

8. Frank RM, Voegel JC. Ultrastructure of the human odontoblast process and its mineralisation during dental caries. Caries Res 1980; 14(6): 367-80. [Crossref]

9. Ekstrand KR, Kuzmina l, Bjørndal L, Thylstrup A. Relationship between external and histologic features of progressive stages of caries in the occlusal fossa. Caries Res 1995; 29(4): 243-50. [Crossref]

10. Pitts N. "ICDAS" - An international system for caries detection and assessment being developed to facilitate caries epidemiology, research and appropriate clinical management. Community Dental Health 2004; 2I(3): 193-8.

II. Zero DT. Dental caries process. Vol. 43, Dental clinics of North America. 1999.p.635-64.

12. Zandona AF, Zero DT. Diagnostic tools for early caries detection. J Am Dent Assoc. 2006 Dec;137(12):1675-84; quiz 1730. [Crossref]

13. Kohara EK, Abdala CG, Novaes TF, Braga MM, Haddad AE, Mendes FM. Is it feasible to use smartphone images to perform telediagnosis of different stages of occlusal caries lesions? PLoS One 2018; 13(9): e0202116. [Crossref]

14. Estai M, Kanagasingam Y, Huang B, Shiikha J, Kruger E, Bunt S, et al. Comparison of a Smartphone-Based Photographic Method with Face-to-Face Caries Assessment: A Mobile Teledentistry Model. Telemed J E Health 2017; 23(5): 435-40. [Crossref]

15. Abufarwa M, Noureldin A, Campbell PM, Buschang PH. Reliability and validity of FluoreCam for white-spot lesion detection: An in vitro study. J Investig Clin Dent 2018; 9(I). [Crossref]

16. Yılmaz H, Keleș S. Recent Methods for Diagnosis of Dental Caries in Dentistry. Meandros Med Dent J 2018; 19(I): I-8. [Crossref]

17. Korkut B, Korkut D, Yanikoglu F, Tagtekin D. Clinical assessment of demineralization and remineralization surrounding orthodontic brackets with FluoreCam. Asian Pac J Trop Biomed 2017; 7(4): 373-7. [Crossref]

18. NouhzadehMalekshah S, Fekrazad R, Bargrizan M, Kalhori KA. Evaluation of laser fluorescence in combination with photosensi- tizers for detection of demineralized lesions. Photodiagnosis Photodyn Ther 2019; 26: 300-5. [Crossref]

19. Rodrigues JA, Sarti CS, Assunção CM, Arthur RA, Lussi A, Diniz MB. Evaluation of laser fluorescence in monitoring non-cavitated caries lesion progression on smooth surfaces in vitro. Lasers Med Sci 2017; 32(8): 1793-800. [Crossref]

20. Terrer E, Koubi S, Dionne A, Weisrock G, Sarraquigne C, Mazuir A, et al. A new concept in restorative dentistry: Light-induced fluorescence evaluator for diagnosis and treatment: Part I - diagnosis and treatment of initial occlusal caries. J Contemp Dent Pract 2009; 10(6): 86-94. [Crossref]

21. Terrer E, Raskin A, Koubi S, Dionne A, Weisrock G, Sarraquigne C, et al. A new concept in restorative dentistry: LIFEDT-light-induced fluorescence evaluator for diagnosis and treatment: Part 2-treatment of dentinal caries. J Contemp Dent Pract 20I0; II(I): 95-I02. [Crossref]

22. Kockanat A, Unal M. In vivo and in vitro comparison of ICDAS II, DIAGNOdent pen, CarieScan PRO and SoproLife camera for occlusal caries detection in primary molar teeth. Eur $\mathrm{J}$ Paediatr Dent 2017; 18(2): 99-104.

23. Talwar M, Borzabadi-Farahani A, Lynch E, Borsboom P, Ruben J. Remineralization of Demineralized Enamel and Dentine Using 3 Dentifrices-An InVitro Study. Dent J 2019; 7(3): 91. [Crossref]

24. Korkut B, Tağtekin DA, Yanıkoğlu FC̣. Diș Çürüklerinin Erken Teșhisi ve Teșhiste Yeni Yöntemler: QLF, Diagnodent, Elektriksel İletkenlik ve Ultrasonik Sistem. EÜ Dișhek Fak Derg 20Il; 32: 55-67

25. Longbottom C, Huysmans MCDNJM. Electrical measurements for use in caries clinical trials. J Dent Res 2004; 83 Spec No C: C76-9. [Crossref]

26. Kühnisch J, Söchtig F, Pitchika V, Laubender R, Neuhaus KW, Lussi $A$, et al. In vivo validation of near-infrared light transillumination for interproximal dentin caries detection. Clin Oral Investig 2016; 20(4): 821-9. [Crossref]

27. Sürme K, Kara NB, Yilmaz Y. In Vitro Evaluation of Occlusal Caries Detection Methods in Primary and Permanent Teeth: A Comparison of CarieScan PRO, DIAGNOdent Pen, and DIAGNOcam Methods. Photobiomodul Photomed Laser Surg 2020; 38(2): 105-II. [Crossref]

28. Hicks J, Garcia-Godoy F, Flaitz C. Biological factors in dental caries enamel structure and the caries process in the dynamic process of demineralization and remineralization (part 2). J Clin Pediatr Dent 2004; 28(2): 119-24. [Crossref]

29. Kalender B. Bașlangıç Çürük Lezyonlarının Tedavisi. Turkiye Klin Diș Hekim Restoratif Diș Tedavisi Özel Derg 2017;2: 58-65.

30. Besra $M$, Kumar $\vee$. In vitro investigation of antimicrobial activities of ethnomedicinal plants against dental caries pathogens. 3 Biotech 20I8; 8(5): 257. [Crossref]

31. Ogard B, Seppä L, Rølla G. Professional topical fluoride applications--clinical efficacy and mechanism of action. Adv Dent Res 1994; 8(2): 190-201. [Crossref]

32. Fluoride therapy. Pediatr Dent 2017; 39(6): 242-5.

33. Mendes ACB, Restrepo MR, Bussaneli DG, Zuanon ACC. Use of casein amorphous calcium phosphate (CPP-ACP) on white-spot lesions: Randomised clinical trial. Oral Health Prev Dent 2018; 16: 27-31.

34. Bailey DL, Adams GG, Tsao CE, Hyslop A, Escobar K, Manton DJ, et al. Regression of post-orthodontic lesions by a remineralizing cream. J Dent Res 2009; 88(12): ||48-53. [Crossref]

35. Tagomori S, Morioka T. Combined effects of laser and fluoride on acid resistance of human dental enamel: (with I color plate). Caries Res 1989; 23(4): 225-31. [Crossref]

36. Alqahtani MA, Andreana S, Rumfola JL, Davis E. Effect of diode laser and topical fluoride applications on white-spot lesions in bovine enamel. Gen Dent 2019; 67(6): 45-51.

37. Molaasadollah F, Asnaashari M, Abbas FM, Jafary M. In vitro comparison of fluoride gel alone and in combination with Er, Cr:YSGG laser on reducing white spot lesions in primary teeth. J Lasers Med Sci 2017; 8(4): 160-165. [Crossref] 
38. Baysan A, Whiley RA, Lynch E. Antimicrobial effect of a novel ozone- generating device on micro-organisms associated with primary root carious lesions in vitro. Caries Res 2000; 34(6): 498-50I. [Crossref]

39. Yazıcıoğlu O, Ulukapı H. The investigation of non-invasive techniques for treating early approximal carious lesions: an in vivo study. Int Dent J 2014; 64(I): I-II. [Crossref]

40. Rickard GD, Richardson RJ, Johnson TM, McColl DC, Hooper L. Ozone therapy for the treatment of dental caries. Cochrane Database Syst Rev 2004; (3): CD004I53.

41. Pini NIP, Sundfeld-Neto D, Aguiar FHB, Sundfeld RH, Martins LBM, Lovanido JS, et al. Enamel microabrasion: An overview of clinical and scientific considerations. World J Clin Cases 2015; 3(I): 34. [Crossref]

42. Gu X, Yang L, Yang D, Gao Y, Duan X, Zhu X, et al. Esthetic improvements of postorthodontic white-spot lesions treated with resin infiltration and microabrasion: A split-mouth, randomized clinical trial. Angle Orthod 2019; 89(3): 372-7. [Crossref]

43. Kim Y, Son HH, Yi K, Ahn JS, Chang J. Bleaching effects on color, chemical, and mechanical properties of white spot lesions. Oper Dent 2016; 4I(3): 318-26. [Crossref]
44. Gizani S, Kloukos D, Papadimitriou A, Roumani T, Twetman S. Is Bleaching Effective in Managing Post-orthodontic White-spot Lesions? A Systematic Review. Oral Heal Prev Dent 2020; 18(I): I-I0.

45. Kielbassa AM, Muller J, Gernhardt CR. Closing the gap between oral hygiene and minimally invasive dentistry: a review on the resin infiltration technique of incipient (proximal) enamel lesions. Quintessence Int 2009; 40(8): 663-8I.

46. Paris $\mathrm{S}$, Meyer-lueckel H, Lfen HC, Kielbassa AM. Resin Infiltration of Artificial Enamel Caries Lesions with Experimental Light Curing Resins. Dent Mater J 2007; 26(4): 582-8. [Crossref]

47. Meyer-Lueckel H, Chatzidakis A, Naumann M, Dörfer CE, Paris S. Influence of application time on penetration of an infiltrant into natural enamel caries. J Dent 20II; 39(7): 465-9. [Crossref]

48. Kim S, Kim EY, Jeong TS, Kim JW. The evaluation of resin infiltration for masking labial enamel white spot lesions. Int J Paediatr Dent 20II; 2I(4): 24I-8. [Crossref]

49. Torres CRG, Borges AB, Torres LMS, Gomes IS, De Oliveira RS. Effect of caries infiltration technique and fluoride therapy on the colour masking of white spot lesions. J Dent 20II; 39(3): 202-7. [Crossref]

50. Perdigão J. Resin infiltration of enamel white spot lesions: An ultramorphological analysis. J Esthet Restor Dent 2020; 32(3): 317-24. 